\title{
Faktor-Faktor Yang Mempengaruhi Nasabah Dalam Menggunakan Layanan Digital Banking Dengan Menggunakan Model Unified Theory Of Acceptance And Use Of Technology (UTAUT) Pada PT. Bank Mandiri Cabang Kebumen
}

\author{
Feby Evelyna \\ Universitas Putra Bangsa \\ Email :febyevelyna3@gmail.com
}

\begin{abstract}
The purpose of this study is to determine the performance expectancy, effort expectancy, social influence, facilitating conditions affect customers in using digital banking services. This research method uses quantitative methods with the type of associative research, namely research that aims to determine the relationship between two or more variables. This study proves that performance expectancy, effort expectancy, social influence, facilitating conditions affect customers in using digital banking services. From the results of the study, it can be concluded that the variables of performance expectancy, effort expectancy, social influence, facilitating conditions affect customers in using digital banking services at Bank Mandiri Kebumen Branch.
\end{abstract}

Keywords: performance expectancy, effort expectancy, social influence, facilitating conditions, digital banking services

\section{PENDAHULUAN}

Perkembangan teknologi informasi memberikan dampak secara global terhadap perbankan yaitu sebagai layanan informasi melalui wireless dengan menggunakan teknologi yang terdapat pada smartphone untuk mendukung kelancaran dan kemudahan kegiatan perbankan. Ini merupakan kesempatan bagi dunia perbankan untuk melangkah maju dengan memberikan pelayanan yang lebih baik kepada para nasabahnya yaitu tidak hanya menawarkan kecepatan dalam melakukan transaksi tetapi juga kemudahan serta kenyamanan bagi nasabah untuk melakukan transaksi keuangan maupun non keuangan secara online tanpa mengharuskan nasabahnya untuk datang dan mengantri di bank (Rema \& Setyohadi, 2016).

Saat ini sudah banyak bahkan hampir semua lembaga keuangan konvensional di Indonesia menerapkan sistem bank secara online untuk memudahkan nasabah dalam bertransaksi, persaingan yang sangat ketat, membuat bank berlomba-lomba untuk meningkatkan pelayanan secara maksimal terhadap nasabah salah satu caranya yaitu menerapkan sitem bank secara digital, dimana nasabah dapat mengakses aktivitas transaksi dimana saja tanpa menghabiskan banyak waktu.

Pihak OJK mengatakan bahwa layanan perbankan berbasis teknologi informasi yang umumnya dikenal sebagai electronic banking/digital banking, memudahkan nasabah untuk melaksanakan transaksi keuangan melalui berbagai delivery channel antara lain Automatic Teller Machine (ATM), Electronic Data Capture (EDC), internet banking, Short Messaging Service (SMS) banking, phone banking, maupun mobile banking (Otoritas Jasa Keuangan, 2016). Perkembangan e-banking yang diawali dengan pembukaan ATM yaitu memiliki fungsi utama untuk penarikan tunai. Selanjutnya diikuti dengan penyelenggaraan EDC yang berfungsi 
melayani transaksi pembayaran nasabah. Meningkatnya transaksi melalui channel mobile banking, berdampak pada penurunan transaksi yang dilakukan di kantor cabang. Hal ini menunjukkan kebiasaan/ behavior masyarakat yang mulai mengarah kepada transaksi elektronik perbankan melalui perangkat digital yang memberi kemudahan bagi nasabah.

Maka peneliti tertarik untuk meneliti faktor-faktor apa saja yang menyebabkan asabah dalam menggunakan layanan digital banking. Pada penelitian ini peneliti menggunakan model Unified Theory of Acceptance and Use of Technology (UTAUT) yaitu sebuah model untuk penerimaan teknologi baru yang diusulkan oleh Venkatesh, Morris, Davis, pada tahun 2003 (Venkatesh et al., 2003). Pada model ini, terdapat empat variabel yang memiliki peranan penting sebagai faktor yang memiliki pengaruh yang signifikan terhadap user acceptance dan usage behavior, yaitu erformance expectancy, effort expectancy, social influence, dan facilitating conditions. Disamping itu terdapat empat moderator yakni gender, age, experience dan voluntariness of use, untuk memoderasi dampak dari pada behavioral intention dan use behavior. Model ini juga sudah banyak digunakan oleh peneliti- peneliti yang menguji tingkat penerimaan masyarakat terhadap teknologi baru seperti dalam penelitian Dzulhaida \& Giri (2015), Sedana \& Wijaya (2009), penelitian Handayani \& Sudiana (2015) dan penelitian lainnya.

Rumusan masalah dalam penelitian ini adalah bagaimana pengaruh performance expectancy, effort expectancy, social influence, facilitating conditions berpengaruh terhadap nasabah dalam menggunakan layanan digital banking?. Penelitian ini bertujuan untuk mengetahui pengaruh performance expectancy, effort expectancy, social influence, facilitating conditions berpengaruh terhadap nasabah dalam menggunakan layanan digital banking pada Bank Mandiri Cabang Kebumen.

\section{TINJAUAN PUSTAKA}

Manfaat digitalisasi bank terutama untuk menurunkan biaya operasional, digitalisasi perbankan merupakan investasi jangka panjang. Pihak perbankan dapat menjangkau pasar lebih luas dengan menurunkan anggaran investasi pembukaan cabang pembantu dan kantor kas kecil. Untuk itu, pada tahap awal pihak perbankan perlu melakukan transformasi infrastruktur IT. Seiring dengan pertumbuhan bisnis e-commerce, dunia perbankan pun dituntut untuk bisa mengikuti tren transaksi digital, sampai dengan hadirnya sektor baru di industri dalam bentuk fintech, serta layanan perbankan keuangan berbasis internet di mana jumlahnya semakin meningkat di Indonesia (Marlina Bimo, 2018).

Otoritas Jasa Keuangan menjelaskan bahwa layanan perbankan digital adalah Layanan atau kegiatan perbankan dengan menggunakan sarana elektronik atau digital milik bank, dan/atau melalui media digital milik calon nasabah dan/atau nasabah bank, yang dilakukan secara mandiri. Hal ini memungkinkan calon nasabah dan/atau nasabah bank untuk memperoleh informasi, melakukan komunikasi, registrasi, pembukaan rekening, transaksi perbankan, dan penutupan rekening, termasuk memperoleh informasi lain dan transaksi di luar produk perbankan, antara lain nasihat keuangan (financial advisory), investasi, transaksi sistem perdagangan berbasis elektronik (e-commerce), dan kebutuhan lainnya dari nasabah bank (Otoritas Jasa Keuangan, 2017).

Menurut Chris (2014: 20) bank digital melacak inovasi dalam perbankan dan bagaimana internet seluler mengubah dinamika hubungan konsumen dan perusahaan dengan bank mereka. Alasan perbankan digital lebih dari sekadar platform seluler atau online adalah karena ia menyertakan solusi middleware. Middleware adalah perangkat lunak yang menjembatani sistem operasi atau basis data dengan aplikasi lain. James (2016: 34) menjelaskan bentuk-bentuk paling awal dari perbankan digital yaitu munculnya mesin dan kartu ATM yang diluncurkan pada tahun 1960-an. Ketika internet muncul pada 1980-an dengan broadband awal, jaringan digital mulai 
menghubungkan pengecer dengan pemasok dan konsumen untuk mengembangkan kebutuhan untuk mengembangkan kebutuhan untuk katalog online awal dan sistem perangkat lunak inventaris.

Unified Theory Of Acceptance And Use Of Technology (UTAUT) adalah sebuah model penerimaan teknologi baru yang diusulkan oleh Venkatesh, Morris, Davis, dan Davis (2003). Model UTAUT memiliki empat variabel utama yang memainkan peran penting sebagai determinan langsung dari behavioral intention dan use behavior yakni performance expectancy, effort expectancy, social influence dan facilitating conditions. Disamping itu terdapat empat moderator yakni gender, age, experience dan voluntariness of use, yang diposisikan untuk memoderasi dampak dari variabel-variabel pada behavioral intention dan use behavior.

Performance expectancy didefinisikan sebagai sejauh mana seorang individu percaya bahwa menggunakan sistem akan membantu dia untuk mencapai keuntungan dalam meningkatkan kinerja. Empat konstruksi dari model yang berbeda yang berhubungan dengan performance expectancy adalah perceived usefulness (TAM/TAM2 dan C-TAM-TPB), job-fit (MPCU), relative advantage (IDT) dan outcome expectations (SCT).

Effort expectancy didefinisikan sebagai tingkat kemudahan penggunaan sistem yang akan dapat mengurangi upaya (tenaga dan waktu) individu dalam melakukan pekerjaannya (Dzulhaida \& Giri, 2015). Tiga konstruksi dari model effort expectancy adalah perceived ease of use (TAM/TAM2), complexity (MPCU) dan ease of use (IDT) (Venkatesh, 2003).

Social influences didefinisikan sebagai sejauh mana seorang individu yang dipengaruhi oleh orang-orang yang menganggapnya penting untuk menggunakan sistem tersebut. Pengaruh sosial merupakan faktor penentu terhadap tujuan perilaku dalam menggunakan teknologi informasi yang direpresentasikan sebagai norma subyektif dalam TRA, TAM, TPB, faktor sosial dalam MPCU, serta citra dalam teori difusi inovasi (IDT) (Venkatesh, et al., 2003).

Facilitating conditions didefinisikan sebagai sejauh mana seorang individu percaya bahwa penggunaan sistem dapat menfasilitasi infrastruktur organisasi dan teknis yang ada (Wiratsoko, 2018). Definisi ini menangkap konsep yang diwujudkan oleh tiga konstruksi yang berbeda, yaitu: perceived behavioral control (TPB/ DTPB, C- TAM-TPB), facilitating conditions (MPCU) dan compatibility (IDT) (Venkatesh et al., 2003).

\section{Hipotesis Penelitian}

Beberapa penelitian yang menjadi dasar dilakukannya penelitian ini yaitu Penelitian Trie Handayani dan Sudiana (2015) Analisis Penerapan Model UTAUT (Unified Theory Of Acceptance And Use Of Technology) Perilaku PenggunaSistem Informasi (Studi Kasus: Sistem Informasi Akademik Pada STTNAS Yogyakarta). Berdasarkan analisis, diketahui bahwa variabel Performance Expectancy (PE), Social Influence (SI) dan Facilitating Condition (FC) berpengaruh secara signifikan terhadap Behavioral Intention, sedangkan variabel Effort Expectancy (EE) memberikan hasil yang tidak signifikan. Secara keseluruhan keempat predictor tersebut hanya mampu menjelaskan pengaruh terhadap behavioral intention sebesar 37,6\%. Laidi Subardi (2018) menjelaskan variabel Promosi berpengaruh positif dan signifikan terhadap variabel Kepercayaan Konsumen, variabel Kepercayaan Konsumen berpengaruh positif dan signifikan terhadap variabel Keputusan Penggunaan layanan digital banking. Sedangkan Ary Muthia (2017) menjelaskan dalam penelitiannya bahwa masyarakat di Kecamatan Medan Johor memahami penggunaan layanan digital perbankan dengan tingkat rata-rata pemahaman sebesar 78,75\%. Masyarakat di Kecamatan Medan Johor masih memanfaatkan ATM untuk transaksi. Namun dengan perkembangan teknologi masyarakat Kecamatan Medan Johor mulai mengetahui dan memanfaatkan layanan digital perbankan selain ATM, bisa diliat pada penggun aan internet banking sebesar $25 \%$. 
Harapan kinerja (Performance Expectancy) didefinisikan sebagai tingkat di mana seseorang percaya bahwa menggunakan sistem akan membantu dia memperoleh keuntungan dalam kinerja (Venkatesh et al, 2003). Wiratsoko (2018) menjelaskan bahwa adanya hubungan harapan usaha dengan layanan digital banking. Hal ini menunjukkan adanya peluang nasabah berkeinginan untuk menggunakan sistem layanan digital banking. Maka dari itu, harapan usaha dapat mempengaruhi nasabah dalam menggunakan sistem layanan digital banking.Dzulhaida dan Giri (2015) menjelaskan bahwa masyarakat Indonesia cenderung memiliki kebiasaan apabila akan mengadopsi suatu sistem maka dia akan dipengaruhi oleh pengaruh sosial atau manfaat yang akan didapatkan apabila menggunakan sistem tersebut seperti halnya layanan digital banking. Sedana \& Wijaya (2009) menjelaskan bahwa adanya hubungan Facilitating conditions terhadap peggunaan sistem. Seorang pengguna yang memiliki tingkat kondisi fasilitas yang tinggi dianggap memiliki persepsi yang baik terhadap sistem. Hal ini menunjukkan semakin tinggi peluang nasabah berkeinginan menggunakan sistem digital banking.

Berdasarkan penelitian sebelumnya dapat disusun hipotesis yaitu:

H1 : Diduga Harapan kinerja (performance expectancy) memiliki pengaruh terhadap nasabah dalam menggunakan layanan digital banking (to use the system

H2 : Diduga Harapan usaha (effort expectancy) memiliki pengaruh terhadap nasabah dalam menggunakan layanan digital banking (to use the system).

H3 : Diduga Pengaruh sosial (social influence) memiliki pengaruh terhadap nasabah dalam menggunakan layanan digital banking (to use the system).

H4 : Diduga Kondisi menfasilitasi (facilitating conditions) memiliki pengaruh terhadap nasabah dalam menggunakan layanan digital banking (to use the system).

H5 : Harapan kinerja (performance expectancy), harapan usaha (effort expectancy), pengaruh sosial (social influence), Kondisi menfasilitasi (facilitating conditions) secara simultan memiliki pengaruh terhadap nasabah dalam menggunakan layanan digital banking (to use the system).

\section{METODE PENELITIAN \\ Populasi dan Sampel}

Populasi dalam penelitian ini adalah semua nasabah yang menggunakan layanan digital banking PT Bank Mandiri Cabang Kebumen. Sampel adalah sebagian populasi sebagai subjek kajian untuk diteliti. Metode pengambilan Sampel dalam penelitian ini menggunakan penentuan jumlah sampel dengan menggunakan Non Probability Sampling yaitu teknik pengambilan sampel yang tidak memberikan peluang atau kesempatan yang sama untuk dipilih menjadi sampel (Sugiyono, 2011: 122).

\section{Jenis dan Sumber Data}

Penelitian ini menggunakan data Primer. Data yang digunakan dalam penelitian ini adalah data yang bersumber dari data primer. Data primer adalah data yang dibuat oleh peneliti untuk maksud khusus menyelesaikan permasalahan yang sedang ditanganinya. Data dikumpulkan sendiri oleh peneliti langsung dari sumber pertama atau tempat objek penelitian dilakukan.

\section{Teknik Pengumpulan Data}

Teknik pengumpulan data yang digunakan adalah teknik lapangan (field research). Teknik tersebut dilakukan dengan Kuisioner adalah bentuk metode pengumpulan data menggunakan pertanyaan atau pernyataan secara tertulis yang harus diisi oleh responden sesuai dengan panduan pengisian yang telah ditetapkan peneliti (Sugiono, 2011: 199). Responden pada penelitian ini adalah nasabah yang telah terdaftar menggunakan layanan digital banking pada Bank Mandiri cabang Kebumen. 


\begin{abstract}
ANALISIS DATA
Metode analisis data yang digunakan dalam penelitian ini adalah analisis regresi linier berganda, dianalisis secara kuantitatif (angka-angka) yang dalam perhitungannya menggunakan metode statistik dibantu dengan program pengolah data SPSS 21.0 dan Microsoft Ecxel. Regresi linier berganda adalah regresi linier dimana sebuah variabel terikat (variabel Y) dihubungkan dengan dua atau lebih variabel bebas (X) (Umar, 2011: 126). Analisis ini bermaksud mengetahui bagaimana pengaruh antar variabel independen dengan variabel dependen.

Regeresi berganda dilakukan untuk mengetahui sejauh mana variabel bebas mempengaruhi variabel terikat. Pada regresi berganda terdapat satu variabel terikat dan lebih dari satu variabel bebas. Model hubungan varibel-variabel tersebut dapat disusun dalam fungsi atau persamaan sebagai berikut:

$Y=a+b_{1} X_{1}+b_{2} X_{2}+b_{3} X_{3}+b_{4} X_{4}+e$

Keterangan :

Y : Penggunaan layanan digital banking

a : Konstanta

$\mathrm{X}_{1} \quad$ : Skor dimensi variabel kesatu

$\mathrm{X}_{2} \quad$ : Skor dimensi variabel kedua

$\mathrm{X}_{3} \quad$ : Skor dimensi variabel ketiga

$\mathrm{X}_{4} \quad$ : Skor dimensi variabel keempat $\mathrm{b}_{1}, \mathrm{~b}_{2}, \mathrm{~b}_{3}, \mathrm{~b}_{4}$ : Koefisien regresi parsial

e : Hambatan
\end{abstract}

Pengujian hipotesis adalah suatu langkah untuk melakukan pengujian terhadap suatu keputusan yang belum pasti kebenarannya apakah ditolak atau diterima keputusan tersebut. Dalam pengujian hipotesis, keputusan yang dibuat mengandung ketidakpastian, mengandung risiko karena jawaban sebenarnya bisa benar bisa salah. Ho (hipotesis nihil) : $\gamma 1=0$; artinya tidak terdapat pengaruh positif antara variabel independen terhadap variabel dependen. Ha (hipotesis alternatif) : $\gamma 1 \neq 0$; artinya terdapat pengaruh positif antara variabel independen terhadap variabel dependen. (Umar, 2011: 104). Untuk mengetahui hubungan dan pengaruh antara variabel independen terhadap variabel dependen dengan menggunakan analisis pengujian hipotesis parsial (Uji t), pengujian secara bersama-sama (Uji F), dan uji koefisien determinasi (R2).

\title{
Pengujian Hipotesis Parsial (Uji t)
}

Teknik ini bertujuan untuk mengetahui pengaruh masing- masing variabel independen terhadap variabel dependen yaitu harapan kinerja (performance expectancy, harapan usaha (effort expectancy), pengaruh sosial (social influence), dan kondisi menfasilitasi (facilitating conditions) terhadap penggunaan layanan digital banking. Uji t dapat dilakukan dengan membandingkan nilai $t$ hitung terhadap nilai $t$ tabel, jika $t$ hitung $>t$ tabel maka dapat disimpulkan bahwa variabel $\mathrm{X}$ mempunyai pengaruh terhadap variabel $\mathrm{Y}$, atau dengan melihat nilai signifikansi pada tabel uji t, jika nilai signifikansi $<0,05$ maka dapat ditarik kesimpulan variabel Xn berpengaruh signifikan terhadap variabel Y, begitu pula sebaliknya (Umar, 2011: 194).

\section{Pengujian Simultan (Uji F)}

Uji $\mathrm{F}$ adalah pengujian secara simultan (bersama-sama) untuk mengetahui pengaruh antar masing-masing variabel independen terhadap variabel dependen yaitu harapan kinerja (performance expectancy, harapan usaha (effort expectancy), pengaruh sosial (social influence), dan kondisi menfasilitasi (Facilitating conditions) terhadap penggunaan layanan digital banking. Uji $F$ dapat dilakukan dengan membandingkan nilai $F$ hitung terhadap nilai $F$ tabel, jika $F$ hitung 
$>\mathrm{F}$ tabel maka dapat disimpulkan bahwa secara simultan variabel $\mathrm{X}$ mempunyai pengaruh terhadap variabel $Y$, atau dengan melihat nilai signifikansi pada tabel uji $t$, jika nilai signifikansi $<0,05$ maka dapat ditarik kesimpulan variabel $\mathrm{Xn}$ berpengaruh signifikan secara simultan terhadap variabel Y, begitu pula sebaliknya (Umar, 2011: 193).

\section{Uji Koefisien Determinasi (R2)}

Uji Koefisien Determinasi (R2) yaitu digunakan untuk mengukur seberapa jauh kemampuan model dalam menjelasakan variasi variabel dependen. Nilai koefisien determinasi adalah mulai dari angka 0 (nol) sampai angka 1 (satu). Nilai R2 yang menunjukkan bahwa variabel dalam model tersebut dapat mewakili permasalahan yang akan diteliti, karena dapat menjelaskan variabel yang terjadi pada variabel dependen itu sendiri (Umar, 2011:1)

\section{HASIL DAN PEMBAHASAN}

\section{Karakteristik Responden}

Deskripsi data responden yang akan dijelaskan untuk memberikan gambaran secara umum mengenai penyebaran data yang telah dilakukan di lapangan. Sampel dalam penelitian ini sebesar 100 orang responden. Penelitian dilakukan dengan menyebarkan kuisioner untuk mengambil data pada nasabah Bank Mandiri cabang Kebumen yang telah menggunakan layanan digital banking atau yang sedang menggunakan layanan digital banking. Berikut ini deskripsi dari responden menurut karakteristiknya.

Tabel 1 Karakteristik Responden

\begin{tabular}{llcc}
\hline No & \multicolumn{1}{c}{ Jenis Kelamin } & Jumlah & Persentase \\
\hline 1. & Laki - Laki & 40 & $40 \%$ \\
2. & Perempuan & 60 & $60 \%$ \\
& Total & 100 & $100 \%$ \\
\hline No & \multicolumn{1}{c}{ Umur } & Jumlah & Persentase \\
\hline 1. & $<20$ tahun & 6 & $6 \%$ \\
2. & 20-30 tahun & 62 & $62 \%$ \\
3. & 30-40 tahun & 22 & $22 \%$ \\
4. & $>40$ tahun & 10 & $10 \%$ \\
& Total Pekerjaan & 100 & $100 \%$ \\
\hline No & \multicolumn{1}{c}{ Jumlah } & Persentase \\
\hline 1. & IRT & 4 & $4 \%$ \\
2. & Mahasiswa & 20 & $20 \%$ \\
3. & Pegawai /Karyawan & 18 & $18 \%$ \\
4. & PNS & 16 & $16 \%$ \\
5. & Wiraswasta & 42 & $42 \%$ \\
\hline \multicolumn{1}{c}{ Total } & 100 & $100 \%$ \\
\hline No & \multicolumn{1}{c}{ Layanan } & Jumlah & Persentase \\
\hline 1. & ATM & 10 & $8 \%$ \\
2. & I-banking & 12 & $10 \%$ \\
3. & M-banking & 16 & $12 \%$ \\
4. & SMS banking & 4 & $16 \%$ \\
5. & I-banking \& M-banking & 2 & $4 \%$ \\
6. & I-banking \& SMS banking & 12 & $2 \%$ \\
7. & I-banking, M-banking & & $12 \%$ \\
& SMS banking & & \\
& & &
\end{tabular}




\section{M-banking \& SMS banking}

Total

36

$36 \%$

$100 \%$

\section{Uji Validitas}

Berdasarkan hasil data yang telah dilakukan, diperoleh hasil / skor validitas butir pertanyaan sebagai berikut:

Tabel 2 Hasil Uji Validasi

\begin{tabular}{|c|c|c|c|c|}
\hline Variabel & Item & Pearson Correlation & Sig & Keterangan \\
\hline \multirow{12}{*}{$\begin{array}{l}\text { Performance } \\
\text { Expectancy }\end{array}$} & PE 1 & 0,5674 & 0,000 & Valid \\
\hline & PE 1 & 0,6403 & 0,000 & Valid \\
\hline & PE 3 & 0,7368 & 0,000 & Valid \\
\hline & PE 4 & 0,6278 & 0,000 & Valid \\
\hline & PE 5 & 0,6119 & 0,000 & Valid \\
\hline & PE 6 & 0,2794 & 0,000 & Valid \\
\hline & PE 7 & 0,7730 & 0,000 & Valid \\
\hline & PE 8 & 0,7635 & 0,000 & Valid \\
\hline & PE 9 & 0,7996 & 0,000 & Valid \\
\hline & PE 10 & 0,7267 & 0,000 & Valid \\
\hline & PE 11 & 0,7512 & 0,000 & Valid \\
\hline & PE 12 & 0,7680 & 0,000 & Valid \\
\hline \multirow{10}{*}{$\begin{array}{l}\text { Effort } \\
\text { Expectancy }\end{array}$} & EE1 & 0,7120 & 0,000 & Valid \\
\hline & EE2 & 0,7046 & 0,000 & Valid \\
\hline & EE3 & 0,6949 & 0,000 & Valid \\
\hline & EE 4 & 0,6844 & 0,000 & Valid \\
\hline & EE5 & 0,3194 & 0,000 & Valid \\
\hline & EE 6 & 0,4189 & 0,000 & Valid \\
\hline & EE 7 & 0,3512 & 0,000 & Valid \\
\hline & EE 8 & 0,4489 & 0,000 & Valid \\
\hline & EE 9 & 0,6345 & 0,000 & Valid \\
\hline & EE 10 & 0,6129 & 0,000 & Valid \\
\hline \multirow{7}{*}{$\begin{array}{l}\text { Social } \\
\text { Influence }\end{array}$} & SI 1 & 0,7947 & 0,000 & Valid \\
\hline & SI 2 & 0,7475 & 0,000 & Valid \\
\hline & SI 3 & 0,6731 & 0,000 & Valid \\
\hline & SI 4 & 0,6832 & 0,000 & Valid \\
\hline & SI 5 & 0,4787 & 0,000 & Valid \\
\hline & SI 6 & 0,7396 & 0,000 & Valid \\
\hline & SI 7 & 0,8025 & 0,000 & Valid \\
\hline \multirow{4}{*}{$\begin{array}{l}\text { Facilitating } \\
\text { Conditions }\end{array}$} & FC 1 & 0,8452 & 0,000 & Valid \\
\hline & $\mathrm{FC} 2$ & 0,6950 & 0,000 & Valid \\
\hline & FC 3 & 0,7912 & 0,000 & Valid \\
\hline & $\mathrm{FC} 4$ & 0,5943 & 0,000 & Valid \\
\hline
\end{tabular}

Feby Evelyna - Faktor-Faktor Yang Mempengaruhi Nasabah Dalam Menggunakan Layanan Digital Banking Dengan Menggunakan Model Unified Theory Of Acceptance And Use Of Technology (UTAUT) Pada PT. Bank Mandiri Cabang Kebumen 


\begin{tabular}{lllll}
\hline \multirow{4}{*}{ Digital Banking } & DB 1 & 0,8109 & 0,000 & Valid \\
& DB 2 & 0,8178 & 0,000 & Valid \\
& DB 3 & 0,8493 & 0,000 & Valid \\
& DB 4 & 0,7549 & 0,000 & Valid \\
\hline
\end{tabular}

Sumber: Data primer yang diolah 2021.

Berdasarkan Tabel 2 di atas menunjukkan bahwa butir- butir pertanyaan dalam instrumen adalah valid, dengan dibuktikan $r$ hitung lebih besar dari $r$ tabel. Valid tidaknya suatu pertanyaan dapat dilihat pada perbandingan $r$ hitung (pearson corelation) dengan $r$ tabel. Jika $r$ hitung $>r$ tabel maka pertanyaan-pertanyaan tersebut dinyatakan valid, begitu pula sebaliknya.

\section{Hasil Uji Reliabilitas}

Dalam hal ini pengujian instrumen menggunakan SPSS versi 21.0 yang dapat mengukur reliabilitas dengan uji statistik Cronbach Alpa. Suatu variabel dikatakan reliabel jika memberikan nilai koefisien Cronbach's Alpha lebih besar dari pada 0,60 (Alpha> 0,60) dan jika koefisien Cronbach Alpha yang < 0,60 maka instrumen tersebut dapat dikatakan tidak reliabel.

\section{Tabel 3 Hasil Uji Reliabilitas}

\begin{tabular}{lccc}
\hline No $\quad$ Variabel & $\begin{array}{c}\text { Jumlah } \\
\text { Item }\end{array}$ & $\begin{array}{c}\text { Cronbach's } \\
\text { Alpha }\end{array}$ & Keterangan \\
\hline 1. Performance & 12 & 0,883 & Reliabel \\
$\quad$ Expectancy & & & Reliabel \\
2. Effort Expectancy & 10 & 0,759 & Reliabel \\
3. Social Influence & 7 & 0,825 & Reliabel \\
4. Facilitating & 4 & 0,692 & Reliabel \\
$\quad$ Conditions & & & \\
5. Digital Banking & 4 & 0,806 & \\
\hline
\end{tabular}

Sumber: Data primer diolah (2021)

Berdasarkan Tabel 3 di atas dapat diketahui bahwa pernyataan dalam instrumen yang digunakan dinyatakan reliabel karena hasilnya menunjukkan bahwa nilai Cronbach's Alpha lebih besar dari pada 0,6 artinya bahwa instrumen tersebut dapat dikatakan handal untuk penelitian selanjutnya yang akan menghasilkan kesimpulan yang sama.

\section{Uji Normalitas}

Menurut Ghozali (2012: 160) uji normalitas bertujuan untuk menguji apakah dalam model regresi variabel memiliki distribusi yang normal. Untuk menguji apakah data berdistribusi normal atau tidak dilakukan uji statistik Kolmogorov-Smirnov Test. Residual berdistribusi normal jika memiliki nilai signifikansi $>0,05$.

Tabel 4 Hasil Pengujian Normalitas

\begin{tabular}{ccc}
\hline Variabel & $\begin{array}{c}\text { Kolmogorov-Smirnov } \\
\mathrm{Z}\end{array}$ & Asymp. Sig. (2-tailed) \\
\hline $\begin{array}{c}\text { Unstandardized } \\
\text { Residual }\end{array}$ & 0,926 & 0,358 \\
Sumber: Data primer diolah (2021) &
\end{tabular}


Berdasarkan Tabel 4 diatas menunjukkan bahwa nilai signifikan pada uji kolmogrov smirnov adalah 0.358 lebih besar dari 0,05 . Sehingga dapat disimpulkan bahwa data yang diuji berdistribusi secara normal.

\section{Uji Multikolinieritas}

Uji multikolinieritas digunakan untuk mengetahui ada tidaknya multikolineritas dengan menyelidiki besarnya inter kolerasi antar variabel bebasnya. Ada tidaknya multikolinieritas dapat dilihat besarnya nilai Tolerance dan Variance Inflation Factor (VIF). Jika nilai Tolerance $>0,10$ atau sama dengan nilai VIF $<10$. Hasil uji mulikolinieritas dapat dilihat pada tabel berikut:

Tabel 5 Hasil Pengujian Multikolinearitas

\begin{tabular}{lcc}
\hline Variabel & Tolerance & VIF \\
\hline Performance Expectancy & 0,622 & 1,609 \\
Effort Expectancy & 0,621 & 1,611 \\
Social Influence & 0,614 & 1,630 \\
Facilitating conditions & 0,630 & 1,586 \\
\hline
\end{tabular}

Sumber : data primer diolah (2021)

Untuk menguji multikolinieritas dengan cara melihat nilai VIF masing-masing variabel independen, jika nilai VIF $<10$, maka dapat disimpulkan data bebas dari gejala multikolinieritas. Berdasarkan tabel 5 di atas dapat diketahui bahwa setiap variabel independen memiliki nilai VIF yang lebih kecil dari 10 atau nilai tolerance value yang lebih besar dari 0,10 . Sehingga dapat disimpulkan bahwa dalam penelitian ini tidak terdapat hubungan multikolinearitas antar variabel independen.

\section{Uji Heteroskedastisitas}

Uji heterokedastisitas bertujuan menguji apakah dalam model regresi terjadi ketidaksamaan variance dari residual satu pengamatan ke pengamatan yang lain (Ghozali, 2012: 139). Pengujian pada penelitian ini menggunakan grafik scatterplot antara nilai prediksi variabel dependen yaitu ZPRED dengan residualnya SRESID. Tidak terjadi heteroskedastisitas apabila tidak ada pola yang jelas, serta titik-titik menyebar di atas dan di bawah angka 0 pada sumbu Y.

Tabel 6 Hasil Pengujian Heteroskedastisitas

\begin{tabular}{lcc}
\hline \multicolumn{1}{c}{ Variabel } & Signifikansi & Keterangan \\
\hline Performance Expectancy & 0,368 & 0,05 \\
Effort Expectancy & 0,449 & 0,05 \\
Social Influence & 0,922 & 0,05 \\
Facilitating conditions & 0,080 & 0,05
\end{tabular}

Sumber: Data primer diolah (2020) 
Berdasarkan hasil uji heteroskedastisitas pada Tabel 6 menunjukan bahwa semua variabel independen mempunyai nilai probabilitas signifikansi lebih dari 0.05 , maka dapat disimpulkan bahwa tidak terjadi heteroskedastisitas dalam model regresi.

\section{Uji Regresi Berganda}

Pengujian pengaruh variabel $\mathrm{X}$ terhadap $\mathrm{Y}$ baik secara bersama-sama maupun secara parsial menggunakan metode analisis regresi linier berganda. Berdasarkan uji hipotesis yang telah dilakukan dengan menggunakna bantuan program SPSS (Statistical Pakage for Social Sciency) 21.0, maka hasil regresi pengaruh masing-masing variabel independen terhadap variabel dependen.

\section{Tabel 7 Hasil Pengujian Regresi}

\begin{tabular}{lcccc}
\hline \multicolumn{1}{c}{ Variabel } & \multicolumn{2}{c}{ Standardized Coefficients } & \multirow{2}{*}{ t } & \multirow{2}{*}{ Signifikansi } \\
& $\mathrm{B}$ & Std.Error & & \\
\hline $\begin{array}{l}\text { (Constant) } \\
\text { Performance }\end{array}$ & 0,942 & 0,589 & 1,600 & 0117 \\
$\begin{array}{l}\text { Expectancy } \\
\text { Effort Expectancy }\end{array}$ & 0,387 & 0,143 & 2,700 & 0,010 \\
& 0,412 & 0,194 & 2,125 & 0,039 \\
Social Influence & 0,203 & 0,116 & 1,956 & 0,076 \\
$\begin{array}{l}\text { Facilitating } \\
\text { conditions }\end{array}$ & 0,037 & 0,098 & 2,700 & 0,710 \\
\hline
\end{tabular}

Sumber: Data primer diolah (2021)

Berdasarkan hasil regresi pada Tabel 7, maka diperoleh persamaan linear berganda sebagai berikut:

$Y=0,942+0,387 X_{1}+0,412 X_{2}+0,203 X_{3}+0,037 X_{4}+e$

Dari persamaan regresi dapat dilihat bahwa :

1. Nilai Koefisien regresi performance expectancy sebesar 0,387 yang berarti jika setiap kenaikan 1\% maka penggunaan layanan digital banking meningkat sebesar 38,7\% dengan asumsi variabel independen lainnya konstan. Hal ini berarti performance expectancy berpengaruh positif terhadap digital banking.

2. Nilai Koefisien regresi effort expectancy sebesar 0,412 yang berarti jika setiap kenaikan $1 \%$ maka penggunaan layanan digital banking meningkat sebesar $41,2 \%$ dengan asumsi variabel independen lainnya konstan. Hal ini berarti effort expectancy berpengaruh positif terhadap digital banking.

3. Nilai Koefisien regresi social influence sebesar 0,203 yang berarti jika setiap kenaikan $1 \%$ maka penggunaan layanan digital banking meningkat sebesar 20,3\% dengan asumsi variabel independen lainnya konstan. Hal ini berarti social influence berpengaruh positif terhadap digital banking.

4. Nilai Koefisien regresi facilitating conditions sebesar 0,037 yang berarti jika setiap kenaikan $1 \%$ maka penggunaan layanan digital banking meningkat sebesar $37 \%$ dengan asumsi variabel independen lainnya konstan. Hal ini berarti facilitating conditions berpengaruh positif terhadap digital banking. 
5. Dan jika variabel independen dalam kondisi tetap atau tidak mempengaruhi variabel dependen atau sama dengan 0 maka nilai konstanta sebesar 0,942 .

\section{Uji Signifikansi (Uji-t)}

Pengujian secara parsial dilakukan guna mengetahui ada tidaknya pengaruh dari masing-masing variabel independen terhadap variabel dependen yang terlihat pada Tabel 7.

\section{Pengaruh Performance Expectancy terhadap Digital Banking}

Berdasarkan Tabel 7 dapat dilihat bahwa performance expectancy (harapan usaha) diperoleh nilai t hitung sebesar 2,700 $>$ t tabel 2.014 dengan nilai signifikannya sebesar 0,010<0,05 yang artinya performance expectancy berpengaruh positif dan signifikan terhadap digital banking. Maka dapat disimpulkan $\mathrm{H}_{\mathrm{a}}$ diterima dan $\mathrm{H}_{0}$ ditolak, dengan demikian dapat dikatakan bahwa performance expectancy berpengaruh terhadap digital banking. faktor ini menjadi faktor yang paling berpengaruh diantara faktor-faktor yang lain. Berdasarkan hasil jawaban responden dalam penelitian ini nasabah merasa bahwa penggunaan layanan digital dapat membantu mereka untuk mencapai keuntungan dalam meningkatkan kinerja.

\section{Pengaruh Effort Expectancy terhadap Digital Banking}

Berdasarkan Tabel 7 dapat dilihat bahwa effort expectancy (harapan usaha) diperoleh nilai $\mathrm{t}$ hitung sebesar 2,125 $>$ t tabel 2.014 dengan nilai signifikannya $0,39<0,05$ yang artinya effort expectancy berpengaruh positif dan signifikan terhadap digital banking. Maka dapat disimpulkan $\mathrm{H}_{\mathrm{a}}$ diterima dan $\mathrm{H}_{0}$ ditolak, dengan demikian dapat dikatakan bahwa effort expectancy berpengaruh terhadap digital banking. faktor ini menjadi faktor yang kedua berpengaruh setelah faktor performance expectancy.

\section{Pengaruh Social Influence terhadap Digital Banking}

Berdasarkan Tabel 7 dapat dilihat bahwa social influence (pengaruh sosial) diperoleh nilai $\mathrm{t}$ hitung sebesar $1,956<\mathrm{t}$ tabel 2.014 dengan nilai signifikannya $0,076>0,05$ yang artinya social influence berpengaruh tetapi signifikan terhadap digital banking. Maka dapat disimpulkan $\mathrm{H}_{\mathrm{a}}$ ditolak dan $\mathrm{H}_{0}$ diterima, dengan demikian dapat dikatakan bahwa social influence berpengaruh tapi tidak signifikan terhadap digital banking. Dalam hal ini dapat dikatakan pengaruh social influence terhadap digital bangking lemah.

\section{Pengaruh Facilitating Conditions terhadap Digital Banking}

Berdasarkan Tabel 7 dapat dilihat bahwa facilitating conditions (kondisi menfasilitasi) diperoleh nilai t hitung sebesar $0,375<\mathrm{t}$ tabel 2.014 dengan nilai signifikannya $0,710>0,05$ yang artinya facilitating conditions tidak mempunyai pengaruh signifikan terhadap digital banking. Maka dapat disimpulkan $\mathrm{H}_{\mathrm{a}}$ ditolak dan $\mathrm{H}_{0}$ diterima, dengan demikian dapat dikatakan bahwa facilitating conditions tidak berpengaruh terhadap digital banking.

\section{Uji Koefisien Determinasi $\left(\mathbf{R}^{\mathbf{2}}\right)$}

Uji Koefisien Determinasi (R2) yaitu digunakan untuk mengukur seberapa jauh kemampuan model dalam menjelasakan variasi variabel dependen. Nilai koefisien determinasi adalah mulai dari angka 0 (nol) sampai angka 1 (satu). Nilai R2 yang menunjukkan bahwa variabel dalam model tersebut dapat mewakili permasalahan yang akan diteliti, karena dapat menjelaskan variabel yang terjadi pada variabel dependen itu sendiri (Umar, 2011:1)

$\mathrm{R}$ diperoleh sebesar 0,674 yang menunjukkan bahwa derajat hubungan antara variabel dependen $\mathrm{Y}$ dengan variabel Independen $\mathrm{X}$ adalah sebesar 67,4\%. Kemudian, nilai $\mathrm{R}$ Square yang diperoleh sebesar 0,455. Oleh karena itu dapat dikatakan bahwa 45\% variasi nilai digital banking yang dapat dijelaskan oleh variabel performance expectanc, effort expectancy, social influence, 
dan facilitating conditions, sisanya sebesar 55\% dijelaskan oleh variabel lain.

\section{PEMBAHASAN}

\section{Pengaruh Performance Expectancy dalam Menggunakan Layanan Digital Banking}

Berdasarkan pengujian hipotesis yang pertama diketahui bahwa Ha yang diajukan dapat diterima. Nilai-nilai yang disajikan pada tabel dapat dilihat bahwa semua koefisien regresi variabel X1 bernilai positif. Hal ini menunjukkan bahwa performance expectancy (harapan kinerja) yang menaikkan penggunaan layanan digital banking sebesar 38,7\% setiap kenaikan 1\%. Dari hasil penelitian dapat dikatakan bahwa variabel X1 (performance expectancy) memberikan pengaruh positif paling besar terhadap digital banking dengan nilai signifikan 0,010 $<0,05$ yang artinya performance expectancy berpengaruh positif dan signifikan terhadap digital banking.

Hasil penelitian pengaruh performance expectancy terhadap digital banking sesuai dengan hasil yang ditemukan oleh Venkatesh et al. (2003). Hasil penelitiannya menunjukkan bahwa harapan kinerja (HK) mempunyai pengaruh positif yang signifikan terhadap keinginan menggunakan sistem (BIUS). Hasil ini juga didukung oleh penelitian Yu (2012), Wiratsoko (2018) dan Prasetyo (2017) yang menemukan adanya pengaruh yang kuat dan signifikan antara harapan kinerja terhadap keinginan seseorang dalam menggunakan sistem. Berdasarkan hasil jawaban responden dalam penelitian ini nasabah merasa bahwa penggunaan layanan digital dapat membantu mereka untuk mencapai keuntungan dalam meningkatkan kinerja.

\section{Pengaruh Effort Expectancy dalam Menggunakan Layanan Digital Banking}

Berdasarkan pengujian hipotesis yang kedua diketahui bahwa Ha yang diajukan diterima. Nilai-nilai yang disajikan pada tabel dapat dilihat bahwa semua koefisien regresi variabel X2 bernilai positif. Hal ini menunjukkan bahwa effort expectancy (harapan usaha) yang menaikkan penggunaan layanan digital banking sebesar $41,2 \%$ setiap kenaikan $1 \%$. Dari hasil penelitian dapat dikatakan bahwa variabel X2 (effort expectancy) memberikan pengaruh positif terhadap digital banking. Jika dilihat dari tingkat signifikannya $0,039>0,05$ yang artinya effort expectancy berpengaruh positif dan signifikan terhadap digital banking.

Hal ini didukung oleh penelitian yang ditemukan oleh Venkatesh et al. (2003). Hasil penelitiannya menunjukkan bahwa effort expectancy (harapan usaha) mempunyai pengaruh positif yang signifikan terhadap keinginan menggunakan sistem. Dzulhaida \& Giri (2015) juga menunjukkan bahwa karakteristik masyarakat Indonesia cenderung memiliki kebiasaan apabila akan mengadopsi suatu sistem maka dia akan dipengaruhi oleh harapan terhadap kinerja atau manfaat yang akan didapatkan apabila menggunakan sistem tersebut seperti halnya e-money. Berbeda dengan penelitian $\mathrm{Yu}$ (2012) yang menemukan pengaruh yang lemah dan tidak signifikan effort expectancy terhadap keinginan seseorang menggunakan sistem, di bidang mobile banking. Dalam penelitian Handayani dan Sudiana (2015) juga menemukan

pengaruh yang lemah dalam hal penggunaan teknologi informasi. Dalam hal internet banking penelitian.

\section{Pengaruh Social Influence dalam Menggunakan Layanan Digital Banking}

Berdasarkan pengujian hipotesis yang ketiga diketahui bahwa Ha yang diajukan ditolak. Nilai-nilai yang disajikan pada tabel dapat dilihat bahwa semua koefisien regresi variabel X3 bernilai positif. Hal ini menunjukkan bahwa social influence (pengaruh sosial) yang menaikkan penggunaan layanan digital banking sebesar 20,3\% setiap kenaikan 1\%. Dari hasil penelitian dapat dikatakan bahwa variabel X3 (social influence) memberikan pengaruh positif terhadap digital banking. Akan tetapi jika dilihat dari tingkat signifikannya 0,076 >0,05 yang artinya social influence berpengaruh positif dan signifikan terhadap digital banking artinya pengaruh 
yang dirasakan tidak terlalu kuat.

Hasil penelitian social influence terhadap digital banking sesuai dengan hasil yang ditemukan oleh Wiratsoko (2018), hasil penelitiannya menunjukkan bahwa pengaruh dari social influence terhadap digital banking hanya 33\% saja, itu artinya pengaruh yang dimiliki tidak terlal kat terhadap sistem. Venkatesh et al. (2003) ketika mempelajari model yang dianalisis untuk menciptakan UTAUT. Menurut Venkatesh et al. (2003) hal ini terjadi karena probabilitas orang memenuhi harapan orang lain lebih besar ketika seseorang mampu memberi hadiah atau imbalan .Namun pada penelitian Dzulhaida dan Giri (2015) terdapat adanya pengaruh yang signifikan. Hal ini menunjukkan bahwa karakteristik masyarakat Indonesia cenderung memiliki kebiasaan apabila akan mengadopsi suatu sistem maka dia akan dipengaruhi oleh harapan responden ter hadap kinerja atau manfaat yang akan didapatkan apabila menggunakan sistem tersebut.

\section{Pengaruh Facilitating Conditions dalam Menggunakan Layanan Digital Banking}

Berdasarkan pengujian hipotesis yang keempat diketahui bahwa Ha yang diajukan dapat diterima. Nilai-nilai yang disajikan pada tabel dapat dilihat bahwa semua koefisien regresi variabel X4 bernilai positif. Hal ini menunjukkan bahwa facilitating conditions (kondisi menfasilitasi) yang menaikkan penggunaan layanan digital banking sebesar $37 \%$ setiap kenaikan 1\%. Dari hasil penelitian dapat dikatakan bahwa variabel X4 memberikan pengaruh positif terhadap digital banking. Akan tetapi jika dilihat dari tingkat signifikannya $0,710>0,05$ yang artinya facilitating conditions tidak mempunyai pengaruh positif dan signifikan terhadap digital banking.

Hasil penelitian ini sesuai dengan penelitian Sedana \& Wijaya (2009), Yuen et al. (2010) dan Martins et al. (2014), yang menjelaskan bahwa tidak ada hubungan antara kondisi fasilitas dan penggunaan sistem. Ini mengindikasikan bahwa layanan digital banking dirancang untuk pengguna umum, sehingga semua konsumen di Kebumen dapat mengakses ataupun mendapatkan fasilitas yang sama dengan mudah. Akan tetapi penelitian ini tidak sesuai denga hasil yang ditemukan oleh Venkatesh et al. (2003) dan Dzulhaida \& Giri (2015) ketika membangun model UTAUT.

\section{KESIMPULAN}

Penelitian ini menguji faktor-faktor yang mempengaruhi nasabah dalam menggunakan layanan digital banking dengan menggunakan model unified theory of acceptance and use of technology (UTAUT) pada PT Bank Mandiri Cabang Kebumen. Berdasarkan hasil analisis regresi berganda, pada tingkat signifikansi 0,05 , dapat disimpulkan bahwa hanya satu hipotesis yang diterima. Namun demikian, nilai beta yang positif untuk semua variabel independen menunjukkan semua variabel $\mathrm{X}$ berpengaruh positif terhadap variabel $\mathrm{Y}$. Adapun hasil penelitian dan pembahasan tersebut secara rinci dijelaskan sebagai berikut:

1. Performance expectancy (harapan kinerja) berpengaruh positif dan signifikan terhadap penggunaan layanan digital banking. Pengguna yang memiliki harapan kinerja yang tinggi mempunyai keinginan menggunakan layanan digital banking yang lebih tinggi dari pada pengguna yang memiliki harapan kinerja yang rendah. Hal ini ditunjukkan dengan nilai $=$ 0,387 dan tingkat signifikansinya 0,010 yaitu lebih kecil dari 0,05 .

2. Effort expectancy (harapan usaha) berpengaruh positif dan signifikan terhadap penggunaan layanan digital banking. Hal ini menunjukkan bahwa masyarakat Indonesia cenderung memiliki kebiasaan apabila akan mengadopsi suatu sistem maka dia akan dipengaruhi oleh harapan terhadap kinerja atau manfaat dari kemudahan yang didapatkan apabila menggunakan sistem tersebut seperti halnya layanan digital banking. Hal ini ditunjukkan dengan nilai $=0,412$ dan tingkat signifikansinya 0,039 yaitu lebih kecil dari 0,05 . 
3. Social Influence (pengaruh sosial) berpengaruh positif tetapi tidak signifikan terhadap penggunaan layanan digital banking. Hal ini ditunjukkan dengan nilai $=0,203$ dan tingkat signifikansinya 0,076 yaitu lebih besar dari 0,05 . Pengaruh yang didapatkan tidak terlalu kuat.

4. Facilitating Conditions (kondisi menfasilitasi) berpengaruh positif tetapi tidak signifikan terhadap penggunaan layanan digital banking. Hal ini ditunjukkan dengan nilai $=0,037$ dan tingkat signifikansinya 0,710 yaitu lebih besar dari 0,05 .

5. Secara simultan semua variabel independen dalam penelitian ini yaitu Performance expectancy (harapan kinerja), Effort expectancy (harapan usaha), Social Influence (pengaruh sosial), dan Facilitating Conditions (kondisi menfasilitasi) berpengaruh signifikan terhadap penggunaan layanan digital banking dengan menunjukkan nilai $\mathrm{F}$ hitung sebesar 9,377 > F tabel 2.58 dengan nilai signifikansinya sebesar 0,000 yang lebih kecil dari 0.05 dan nilai $\mathrm{R}$ Square sebesar $45 \%$ yang berarti bahwa variasi nilai digital banking yang dapat dijelaskan oleh variabel performance expectanc, effort expectancy, social influence, dan facilitating conditions, sisanya sebesar 55\% dijelaskan oleh variabel lain.

\section{SARAN}

Berdasarkan kesimpulan pada penelitian ini, peneliti menguji 4 variabel indenpenden yaitu performance expectancy (harapan kinerja), effort expectancy (harapan usaha), social Influence (pengaruh sosial), dan facilitating conditions (kondisi menfasilitasi) terhadap satu variabel dependen yaitu layanan digital banking. Hanya performance expectancy (harapan kinerja) yang paling signifikan pengaruhnya. Oleh karena itu, penulis menyarankan beberapa hal sebagai berikut:

1. Bagi Perbankan

Berdasarkan hasil penelitian khususnya Bank Syariah Mandiri harus mempertahankan kinerjanya akan tetapi juga harus meningkatkan variabel lainnya yaitu effort expectancy (harapan usaha), social Influence (pengaruh sosial), dan facilitating conditions (kondisi menfasilitasi) karena ketiga variabel tersebut sebenarnya berpengaruh terhadap digital banking akan tetapi tidak signifikan.

\section{Bagi Peneliti}

Untuk penelitian lebih lanjut dapat dilakukan dengan menambah atau mengganti variabel independen dengan variabel lain yang tidak disebutkan dalam penelitian ini seperti faktor keamanan, faktor biaya dan variabel-variabel lainnya untuk meneliti kembali sehingga sisanya $54 \%$ dapat terpenuhi.

\section{DAFTAR PUSTAKA}

Ajzen, I. (1991). The Theory of Planned Behavior. Organizational Behavior and Human Decision Processes Vol. 50, No. 2.

Anggraeni, Y. (2016). Pengaruh Pelayanan Berbasis Teknologi Informasi Terhadap Kepuasan Nasabah Bank Di Kota Semarang. Skripsi.

Bank Indonesia. (2015). Statistik Perbankan Indonesia. Diambil kembali dari Statistik Bank Indonesia: diakses pada 13 November 2018

http://www.bi.go.id/id/statistik/sistempembayaran/uangelektronik/contents/jumlah\%20uang $\% 20$ elektronik.aspx

Bungin, B. (2010). Metodologi Penelitian Kuantitatif, Komunikasi, Ekonomi, Dan Kebijakan Publik Serta Ilmu-ilmu Sosial Lainnya. Jakarta: Kencana. Ed.1, Cet. 5.

Chris, S (2014). Digital Bank: Strategies to launch or become a digital bank BusinessPro collection. Singapore : Marshall Cavendish International Asia Pte Ltd. 
Compeau, D. R., \& Higgins, C. A. (1991). A Social Cognitive Theory Perspective on Individual Reactions to Computing Technology. New York: International Conference on Information Sistems (ICIS).

Davis, F. D. (1989). Perceived Usefulness, Rerceived Ease of Use and User Acceptance of Information Tehnology. MIS Quarterly. Vol. 13, No. 5.

DBS. (2015). Ini Alasan Digital Banking Mempermudah Anda!. Diakses pada 18 November 2018.

Dari https://www.dbs.com/indonesia-bh/blog/live-smart/ini- alasan-digital-bankingmempermudah-anda.pages.

DBS. (2016). Digital Banking New Avatar - Banks Watch Out for Banks. Diakses pada 17

November 2018.https://www.dbs.com/insights/uploads/20161010

_Digital_Banking_Low_Res.pdf.

Dzulhaida, R., \& Giri, R. R. (2015). Analisis Minat Masyarakat Terhadap Penggunaan Layanan E-Money Di Indonesia Dengan Menggunakan Model Modifikasi Unified Theory Of Acceptance And Use Technology 2 (UTAUT 2). Majalah Ilmiah Unikom. Vol.15 No. 2 , 155-166.

Febriana, T. (2014). Studi Penerapan Inovasi Teknologi Informasi Dengan Metode Technology Watch And Competitive Intelligence (TW-CI). Jurnal Binus University. Vol. 5, No.1

Franedya, R. (2016). BSM Kembangkan Layanan E-Banking, Diakses pada 14

November 2018. Dari https:/keuangan.kontan.co.id/news/bsm-kembangkanlayanan-e-banking-1.

Ghozali, I. (2012). Aplikasi Analisis Multivariate Dengan Program SPSS. Semarang: Badan Penerbit Universitas Diponegoro.

Hair, J. F., Black, W. C., Babin, B. J., Anderson, R. E \& Tatham, R. L. (2006). Multivariate Data Analysis (6th ed). Upper Saddle River: Pearson Education

Handayani, T., \& Sudiana. (2015). Analisis Penerapan Model UTAUT (Unified Theory Of Acceptance And Use Of Technology) Terhadap Perilaku Pengguna Sistem Informasi (Studi Kasus: Sistem Informasi Akademik Pada Sttnas Yogyakarta). JURNAL ANGKASA. Vol. VII, No. 2. hal. 165- 180.

Hermawan, A. (2005). Penelitian bisnis paradigma kuantitatif. Jakarta: Kencana.

James, K. (2016). The History of Banking: A Comprehensive Reference Source\& Guide. CreateSpace Independent Publishing Platform.

Kompas.com.(2017). Diakses pada $15 \quad$ November 2018. Dari https://ekonomi.kompas.com/read/2017/05/16/120932726/tra

nsformasi.perbankan.digital.yang.tidak.sekadar.digital.lipstic k.

Marlina, A., \& Bimo, W. A. (2018). Digitalisasasi Bank Terhadap Peningkatan Pelayanan Dan Kepuasan Nasabah Bank. Jurnal Ilmiah Inovator.

Martins, C., Oliveira, T., Popovic. A., (2014). Understanding the Internet banking adoption: A unified theory of acceptance and use of technology and perceived risk application. International Journal of Information Management, Vol.34, No. 1.

Marliza, (2017). Aplikasi Dan Keunggulan E-Banking Pada PT. Bank Syariah Mandiri KCP Aceh Darussalam. 
Moore, G. C., \& Benbasat, I. (1991). Development of an Instrument to Measure the Perceptions of Adopting an Information Technology Innovation. The Institute of Management Sciences, Information Sistems Research Vol. 2, No. 3

Muthia, A. (2017). Analisis pemahaman masyarakat kecamatan medan johor terhadap penggunaan layanan digital Perbankan. Skripsi.

Nicoletti, B. (2014). Mobile Banking : Evolution or Revolution? Palagrave Studies in Financial Services Teknology. Italy: Springer.

Nurgiyantoro, B. (2012). Penilaian Pembelajaran Bahasa. Yogyakarta: BPFE

Oshlyansky., Lidia., Paul, C., \& Harold, T. (2016). Validating the Unified Theory of Acceptance and Use of Technology (UTAUT) Tool Cross-Culturally. BCS learning \& Development Ltd. United Kingdom: Swindon.

Otoritas Jasa Keuangan. (2016). Draft: Task Force Digital Banking. Diakses pada 13November 2018. Dari http://www.ojk.go.id/berita-dan-kegiatan/pengumuman/Documents/Draf-CPDigital- Bangking

Otoritas Jasa Keuangan. (2017). Panduan Penyelenggaraan Digital Branch Oleh Bank Umum. Diakses pada 17 September 2018: https://www.ojk.go.id/id/kanal/perbankan/Pages/Pandu an-Penyelenggaraan-Digital-Branch-oleh-Bank-Umum. pdf

Oye, N. D., Iahad, N. A., \& Rahim, N. A. (2014). The history of UTAUT model and its impact on ICT acceptance and usage by academicians. Adamawa State University: Educ Inf Technology.

Pinontoan, W. (2013). Pengaruh E-Banking, Kualitas Pelayanan, Kualitas Komunikasi Dan Kepercayaan Terhadap Loyalitas Nasabah Pada Pt. Bank Mandiri Cabang Manado. Jurnal EMBA Vol.1 No.4.

Prasetyo, Y. D. (2017). Penerapan Metode Utaut (Unified Theory Of Acceptance And Use Of Technology) Dalam Memahami Penerimaan Dan Penggunaan Website Kkn Lppm Unisi. Jurnal Sistemasi, Volume 6, Nomor 2.

Quesada, V. (2017). When Tech Meets Finance: A Roadmap for Digital Banking Transformation. Massachusetts: CreateSpace Independent Publishing Platform. Edisis kedua

Rema, Y. O., \& Setyohadi, B, D. (2016). Faktor-Faktor Yang Mempengaruhi Penerimaan Mobile banking studi kasus : bri cabang bajawa. Skripsi.

Subardi, L. (2018). Pengaruh Promosi Dan Kepercayaan Nasabah Terhadap Keputusan Penggunaan Layanan Digital Di Bank Sumsel Babel Cabang Prabumulih. ISSN : 2540-816X Vol. 3 No. 2.

Sedana, N.G \& Wijaya, W. (2009). Penerapan Model UTAUT Untuk Memahami Penerimaan Dan Penggunaan Learning Management System. Journal of Information Systems, Vol. 5, No. 2

Sugiyono, (2011). Metode Penelitian Pendidikan (Pendekatan Kuantitatif, Kualitatif, dan R\&D). Bandung: Alfabeta.

Thompson, R. L., Christopher, A., Higgins \& Jane, M. H. (1991). Personal Computing: Toward a Conceptual Model of Utilization. Management Information Sistems Research Center, University of Minnesota.

Umar, H. (2011). Metode Penelitian Untuk Skrips dan Tesis Bisnis Edisi Kedua. Jakarta: Rajawali. 
Yanuar, I. (2015). OJK terus dukung era digitalisasi perbankan syariah. Diakses pada 15 November 2018. Dari https://www.viva.co.id/arsip/672866-ojk-terusdukung-era- digitalisasi-perbankan-syariah.

Yudhi, W., Arthana, R., \& Rukhviyanti, N. (2015). Pengaruh Minat Individu Terhadap Penggunaan Mobile Banking (M- Banking): Model Kombinasi Technology Acceptance Model (TAM) dan Teory Of Planned Behavior (TPB)", Jurnal Informasi. Vol. 7, No. 1.

Yu, C.S., (2012). Factors affecting individuals to adopt mobile banking: empirical evidence from the UTAUT model. Journal of Electronic Commerce Research Vol. 13 No.2

Yuen Y.Y., Yeow P.H.P., Lim N., Saylani N., (2010). Internet banking adoption: Comparing developed and developing countries. The Journal of Computer Information Systems, Vol. 51, No. 1 